Article

\title{
Laser Welding on Cerclage Wire Joining in Femur Surgery
}

\author{
Nutchanat Thongchuea ${ }^{1}$, Eakkachai Warinsiriruk ${ }^{1}$ and Yin-Tien Wang ${ }^{2, *}$ (D) \\ 1 Department of Industrial Engineering, Mahidol University, Nakhon Pathom 73170, Bangkok, Thailand; \\ nutchanat.tho@student.mahidol.edu (N.T.); eakkachai.war@mahidol.ac.th (E.W.) \\ 2 Department of Mechanical and Electro-Mechanical Engineering, Tamkang University, \\ New Taipei City 25137, Taiwan \\ * Correspondence: ytwang@mail.tku.edu.tw; Tel.: +886-2-2621-5656 (ext. 3280)
}

Received: 18 December 2019; Accepted: 29 March 2020; Published: 1 April 2020

Featured Application: The proposed method of laser welding on lap joints is featured with large joint strength and less loosening failure and has a potential application on modern femur surgery.

\begin{abstract}
Stainless steel wires with fiber-laser welding on lap joints are first proposed in this study to be used as cerclage wire joints for modern femur surgery, because of their potentially larger joint strength and less loosening failure than traditional joint devices. In this feasibility study, an experiment was set up to determine adequate parameters for the laser welding process in order to ensure that the wire joint of cerclage has good weld appearance, free oxidation, and suitable joint strength. A stainless steel wire 316L with a diameter of $1.6 \mathrm{~mm}$, flare-welded on lap joint was used in the experiment as a specimen cerclage wire joint. Two major effective parameters were chosen for controlling a suitable fusion weld, including charge voltage and multiple frequencies of the laser irradiation. The adequate area of the laser parameters was determined from the experiment, including the ranges of charge voltage, multiple frequencies, and pulse width. The suitable welded lengths of specimens were also studied in the mechanical test to validate the joint strength. Suggested welded length has a better tensile strength than traditional cerclage joints. The paper concludes that the stainless wire joints with a fiber laser weld represents a promising alternative to traditional cerclage joint devices for modern femur surgery.
\end{abstract}

Keywords: cerclage wire; robot-assisted laser welding; laser welding parameters; wire joint tensile strength

\section{Introduction}

Cerclage wire is a common procedure of orthopaedic surgeons for internal fixation. It also helps as a tool for arranging femoral bone fracture. Currently, this surgery method has an indication for the treatment of multiple bone fractures such as periprosthetic fracture, femoral fracture or patellar fracture, etc. [1-7]. Stevens et al. mentioned that the attachment of plates using cerclage wires obviated the need for screws and a double-loop cerclage performed better than a single-loop one [1]. Cerclage wiring technique helps to achieve stable reduction of femoral fractures which can then be supplemented with a nail or a plate $[2,3]$. For clinical use, the treatments using cerclage wires with locking plate fixation for periprosthetic fractures of the femur promoted faster time to union, less complication, and fewer revisions [4]. The literature [5,6] also presented that many cerclage-wiring technologies in difficult femoral fractures offered a minimally invasive reduction and fixation technique, low cost, and early holding. 
Cerclage and tension band wiring techniques can be inexpensively and effectively utilized in orthopedic surgical procedures, many of which are enumerated in the literatures [5-7]. A cerclage wire is usually bundled around two fractured bones then twisted at the end of wire to form a knot as shown in Figure 1a, or locked using a device called the crimp as shown in Figure 1b. Figure 2 is an example of fracture bone bundled with cerclage wires. Twisting is clinically the most frequently applied method for tightening and maintaining cerclage fixation [8]. Many techniques for wire twists were developed and experimentally tested in the literature. The results concluded that fastening twists were stronger than crimp techniques $[9,10]$. However, cerclage wires still have problems in fixation failure which untwist failure or broken wire often occurs at the innermost turn of the twists [6-8]. Also, cerclage cable often fails. It was reported that the multifilament structure of the cable could be destroyed by the broken cable at the crimp [11]. Moreover, a cerclage cable can be loosened during surgery immediately after clamping the cable with a crimp [12]. These weak points of cerclage wires and cables result in a decrease in the efficiency of bone fracture treatment [11]. Furthermore, if surgeons fasten the wire with less tension force, wire loosening after surgery causes fixation failure as well $[7,9,10]$. As a result, the patients might suffer from repeating surgery operations. Therefore, the knot of the cerclage wire is the critical point to measure the achievement in treatment.

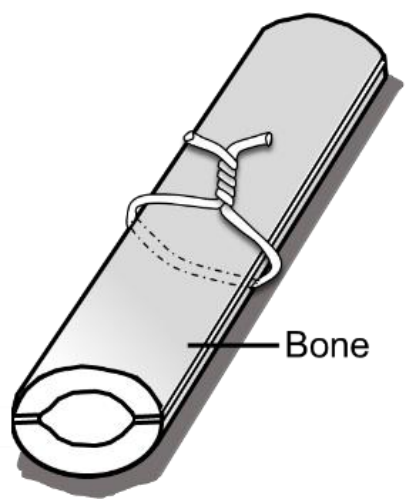

(a)

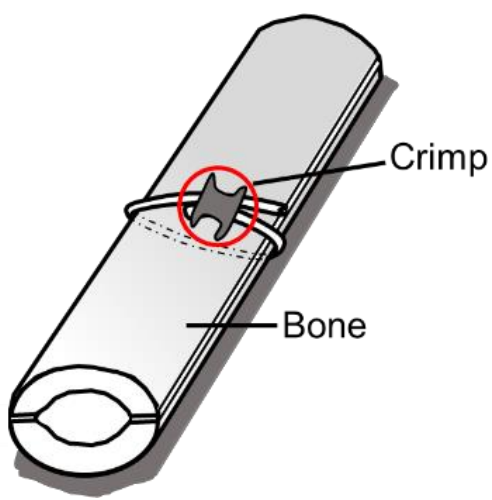

(b)

Figure 1. Type of cerclage (a) cerclage wire, (b) cerclage cable.

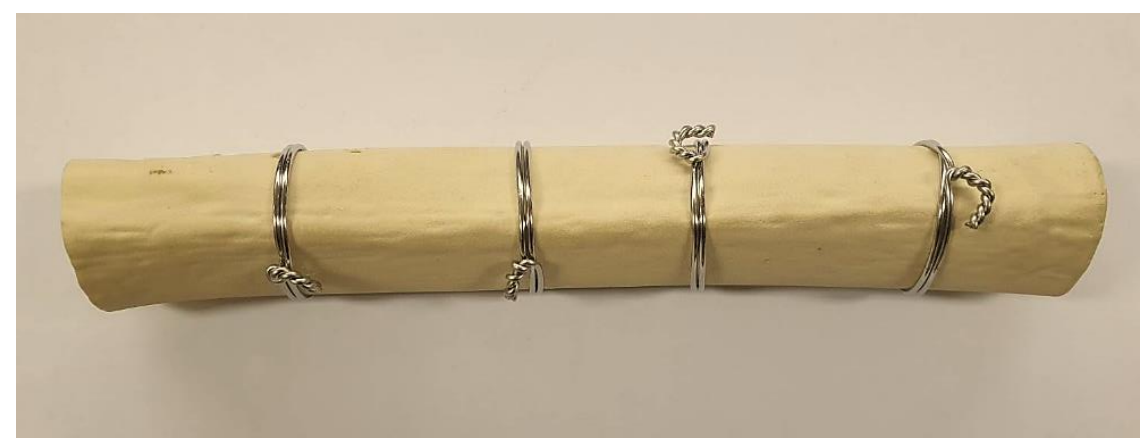

Figure 2. An example of fracture bone bundled with cerclage wires.

In the study, laser techniques are proposed to weld the joints of cerclage wires [13]. As the laser has low power and high accuracy properties, the laser welding has the capacity to improve the quality and strength of common cerclage joint $[14,15]$. Furthermore, dental laser techniques were applied for treating the patients. Ortorp et al. reported that the use of laser-welded titanium frameworks along with implants in the edentulous mandible to treat patients provide $100 \%$ achievement by following up the patients for 10 years [16]. Fornaini et al. studied the use of Nd: YAG laser to weld titanium for intra-oral implant abutments and inserted it in pig jaws. It was reported that it can provide biomechanical strength and can endure the immediate load including the thermal load and it does not 
harm the bone and surrounding tissues [17-19]. Previous research indicated that laser welding can be used in medicate and treat the patients without the risk of thermal effect to occur on the bone and surrounding tissues.

Therefore, the laser technology is offered to prevent the cerclage wire from loosening and to reduce the broken crimp of the cerclage cable through the fused weld joint. In this research, a modern femur surgery using cerclage wires was investigated. Furthermore, a bench-scale laboratory test was implemented on a double-loop cerclage wire with fiber-laser welding on the lap joint as shown in Figure 3a. In this preliminary study, the laser welding experiments were conducted to determine the laser parameters for controlling the weld profile $[20,21]$ on the lap joint which has a wire diameter of $1.6 \mathrm{~mm}$, as shown in Figure 3b.

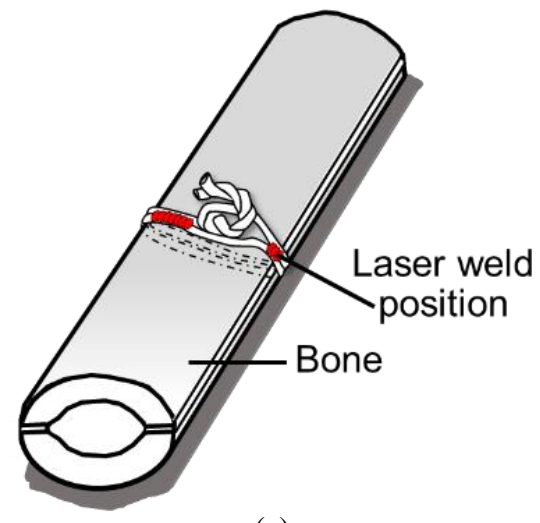

(a)

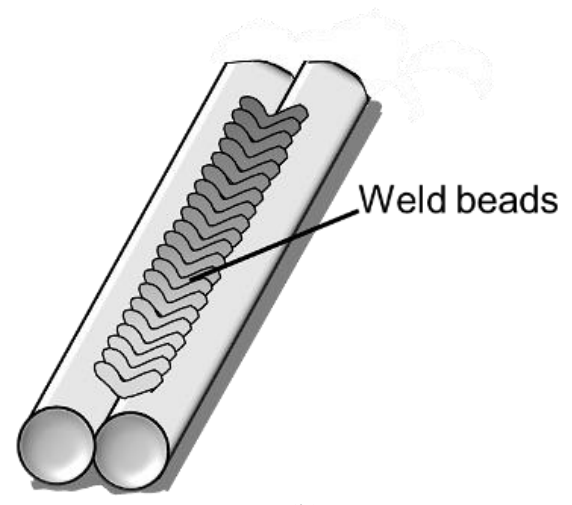

(b)

Figure 3. Type of proposed cerclage (a) cerclage wire (double loop) and (b) specimen with laser welding.

\section{Methods}

In femur surgery, the fractured bones are bundled using a cerclage wire, then twisted at the end of wire. Cerclage wire still has problems in fixation failure or wire loosening. In this study, we propose to apply the laser welding on the lap joints and used as cerclage wire joints for modern femur surgery. Because welded joints have the potential of larger joint strength and less loosening failure than that of traditional joint devices.

In the metal welding process, two or more pieces of metal welded together to form a welded joint which consists of base metal, weld metal, fusion zone and heat affected zone $[15,21]$. The welding process at the joint is a series of complicated processes such as local heating, metal melting and solidification, therefore, the welded joint is a region with heterogeneous ingredients, organization and mechanical properties [22,23]. The properties of the welding joint are affected by the process parameters of the laser welding such as frequency, beam power, focal length, defocus, spot size, welding beam speed, and shielding gas flow [24]. The weld appearance, i.e., the dimensions of bead width and bead height, is usually used to represent the effect of parameters as well as the process ability of laser welding [24]. In this study, we focused on the process parameters, including the ranges of charge voltage, multiple frequency, and pulse width.

\section{Welding, Inspection and Mechanical Testing}

In this study, an experimental work was implemented including laser welding on specimens, inspection of weld appearance, and mechanical testing of the specimens. The procedures are explained as the following subsections.

\subsection{Material and Experimental Setup}

In the laser welding process, stainless steel wire $316 \mathrm{~L}$ with diameter $1.6 \mathrm{~mm}$ was used, as shown in Figure 4. The experiment was performed on the laser welding machine AHL - Laser (model XBW- 400). 
The beam source of laser welding in this experiment is Nd:YAG (wavelength $1064 \mathrm{~nm}$ ). The focused length and defocused length of laser machine were $80 \mathrm{~mm}$ and $56 \mathrm{~mm}$, respectively. Two stainless steel wires were aligned with each other using jig fixture for the laser welding process to be performed. The specimen was in the axis with laser head which laser beam was radiated emitted from the laser head. The weld bead between two stainless steel wires was formed and called "flare weld". The argon gas was injected from the gas nozzle to spread on upper- and lower-plane of the specimen during welding process. The purpose of using argon gas to cover the welding area is to prevent oxidation of the specimen. In the experiment, the argon gas shielding was at the flow rate of $10 \mathrm{~L} / \mathrm{min}$; the travel speed of welding was set to be constant at $75 \mathrm{~cm} / \mathrm{min}$. The resultant welded joint of the cerclage wire is shown as Figure 5.

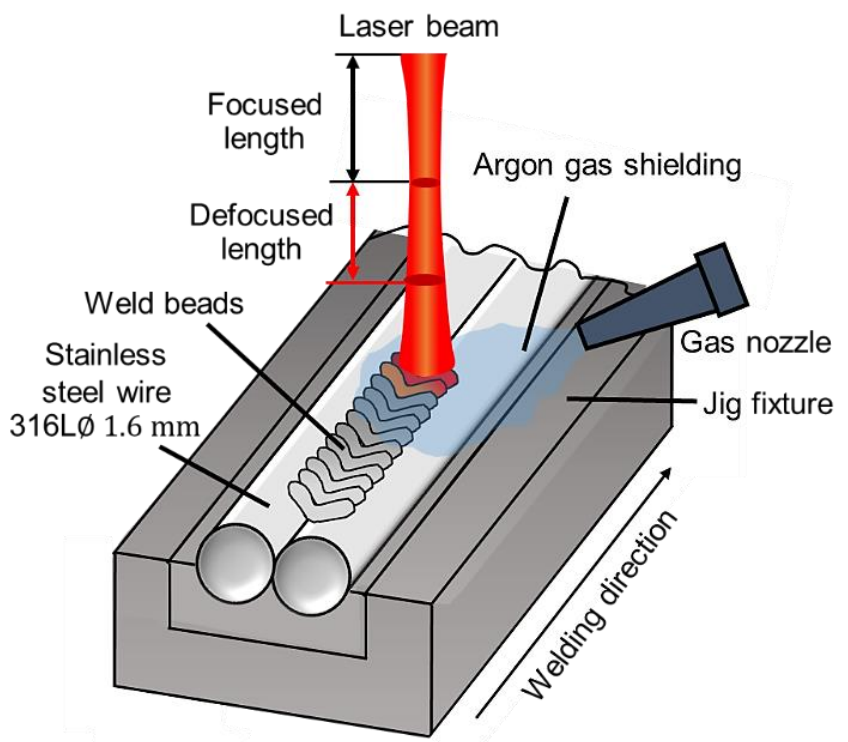

Figure 4. The schematic experimental setup.

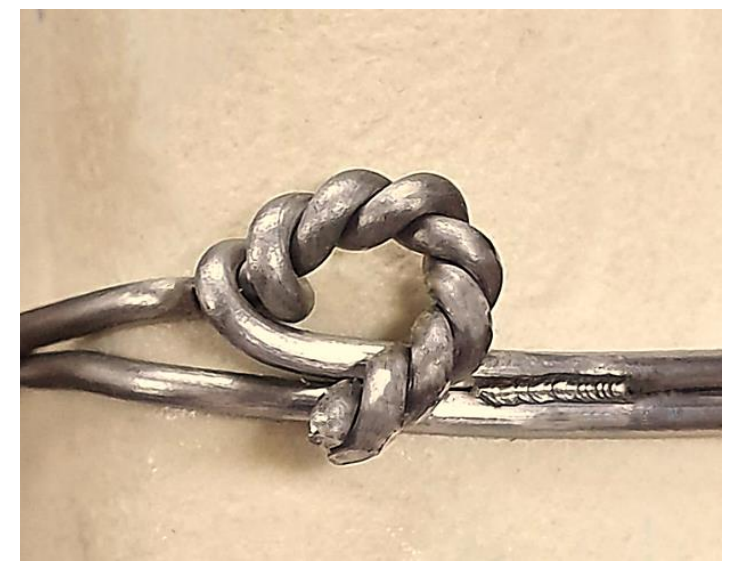

Figure 5. Cerclage wire joints with laser welded.

\subsection{Inspection of Weld Appearance}

In the experiment, two laser parameters were adjusted including the charge voltage $(\mathrm{V})$ and the pulse frequency $(\mathrm{Hz})$, while the pulse width was set to be constant at $3 \mathrm{~ms}$, as shown in Figure 6 . The purpose was to find the upper and the lower bound of the weld appearance which indicated that the weld process was properly performed on stainless steel wire 316L. Figure 6 shows that the upper bound of charge voltage is at $110 \mathrm{~V}$, while the pulse frequency is at $12 \mathrm{~Hz}$. The weld appearance contained oxidation and burns due to overheating at high charge voltage, faster heat accumulation 
at high pulse frequency adjustment, as well as the heat from the welding with inappropriate wire dimension. The charge voltage below the lower bound at $80 \mathrm{~V}$ resulted in the lack of fusion due to insufficient heat to melt the wire. Therefore, for acceptable range of laser parameters, the charge voltage is in the range of $80-110 \mathrm{~V}$ and the pulse frequency is in the range of $6-12 \mathrm{~Hz}$. Notably, at the pulse frequency of $3 \mathrm{~Hz}$, there were many gaps between weld beads that will cause the cavity defect, which might affect the joint strength.

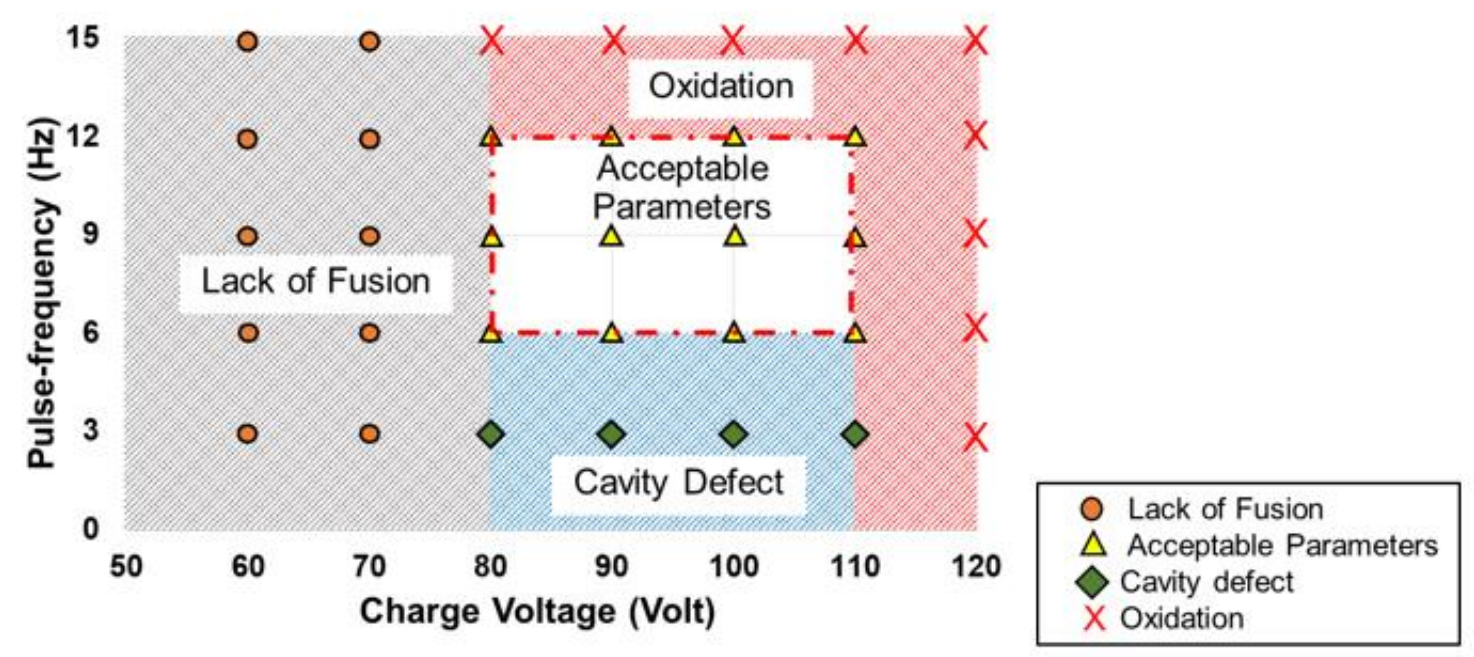

Figure 6. Inspection weld appearance of laser parameters.

In this study, three laser parameters were chosen including charge voltage, pulse frequency, and pulse width in order to evaluate the effects of metal melting. The concept was to design the laser parameters for welding on the stainless steel wire with desired weld width and depth. This was implemented by adjusting the rank of laser parameters for the experiment with the feedback from the inspection of weld appearance. The experimental results are listed in Table 1.

Table 1. Laser welding parameters.

\begin{tabular}{|c|c|c|c|c|}
\hline Parameters & & & & \\
\hline Charge voltage (V) & 80 & 90 & 100 & 110 \\
\hline Pulse frequency $(\mathrm{Hz})$ & 6 & & & 12 \\
\hline Pulse width (ms) & & & & \\
\hline Argon gas shielding (L/min) & & & & \\
\hline Welding speed $(\mathrm{cm} / \mathrm{min})$ & & & & \\
\hline Defocused length (mm) & & & & \\
\hline Beam diameter (mm) & & & & \\
\hline
\end{tabular}

\subsection{Mechanical Testing}

The mechanical properties of joint strength for the laser weld were evaluated by mechanical testing to determine the load and strength of the weld beads. The resultant joint strength depends on the parameters of the laser and the length of welding. The aim of this study was to find the value of ultimate load at the failure from adjusting laser parameters and length of welding. In this study, the adequate area of the laser parameters and the length of welding were evaluated to determine the ultimate load at failure. The ultimate load at failure must be within acceptable range or more than that of previous research. Three experimental variables of welding condition (see Table 2) were used in the testing. Tensile testing was performed on a universal testing machine under a constant cross-head speed of $12.5 \mathrm{~mm} / \mathrm{min}$. The schematic of the flare weld joint under shear loading and load vector direction are shown in Figure 7. 
Table 2. Variables for testing the tensile strength.

\begin{tabular}{crrccc}
\hline Variables & \multicolumn{5}{c}{ Level } \\
\hline Charge voltage $(\mathrm{V})$ & 80 & 90 & & 100 & 110 \\
Pulse frequency $(\mathrm{Hz})$ & 6 & & 9 & 12 \\
Welding length (mm) & 5 & & 10 & 15 \\
\hline
\end{tabular}

Note: pulse width is set at constant of $3 \mathrm{~ms}$

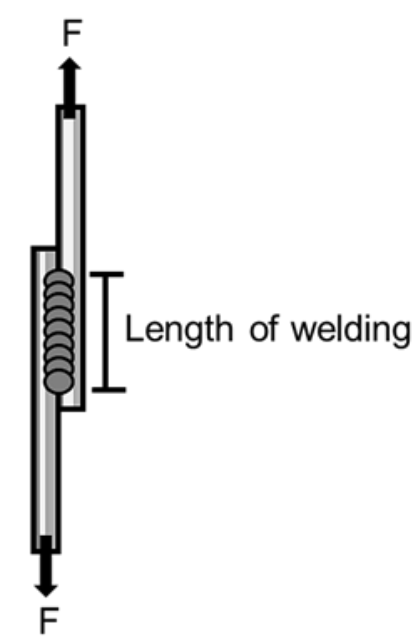

Figure 7. Schematic view of the relationship between shear loading and weld joint.

\section{Experimented Results and Discussion}

\subsection{Effect of Laser Parameters on Weld Bead Width}

In regard with the charge voltage at $80 \mathrm{~V}$, the weld result in Figure 8a shows the example of oxidation region at a high pulse frequency of $15 \mathrm{~Hz}$ with pulse width of $3 \mathrm{~ms}$. A good weld appearance with nice ripples is shown in Figure $8 \mathrm{~b}$ in which the pulse frequency was set at the acceptable range of 6 $\mathrm{Hz}$ with pulse width of $3 \mathrm{~ms}$. In the case of low charge voltage at $70 \mathrm{~V}$, the result in Figure $8 \mathrm{c}$ shows the phenomena for lacking of fusion. Based on the experimental results, the weld appearance, including the weld shape and the bead width, were affected by increasing charge voltage and pulse frequency.

The weld appearance was measured in the experiments and the results were used to investigate the connection between the weld bead width and the set values of charge voltage and pulse frequency. Figure 9 shows the weld bead width obtained at the charge voltage of $80,90,100$, and $110 \mathrm{~V}$, while the pulse frequency was set at $6 \mathrm{~Hz}$ and the pulse width was set at $3 \mathrm{~ms}$. The weld bead width obtained at pulse frequency of 6,9 , and $12 \mathrm{~Hz}$, is shown in Figure 10. The charge voltage was set at $80 \mathrm{~V}$ and the pulse width was set at $3 \mathrm{~ms}$. It can be concluded that the increase of charge voltage and pulse frequency will result in increased bead width because the heat for metal melting is also increased. When the bead width was increased, the sound bead was also increased because the gap area was reduced. The reduction of gap area was due to the increasing of pulse frequency of welding. Based on the results shown in Figure 9, the charge voltage at $110 \mathrm{~V}$ could result in the highest weld bead width which is referred to as the soundest bead. 


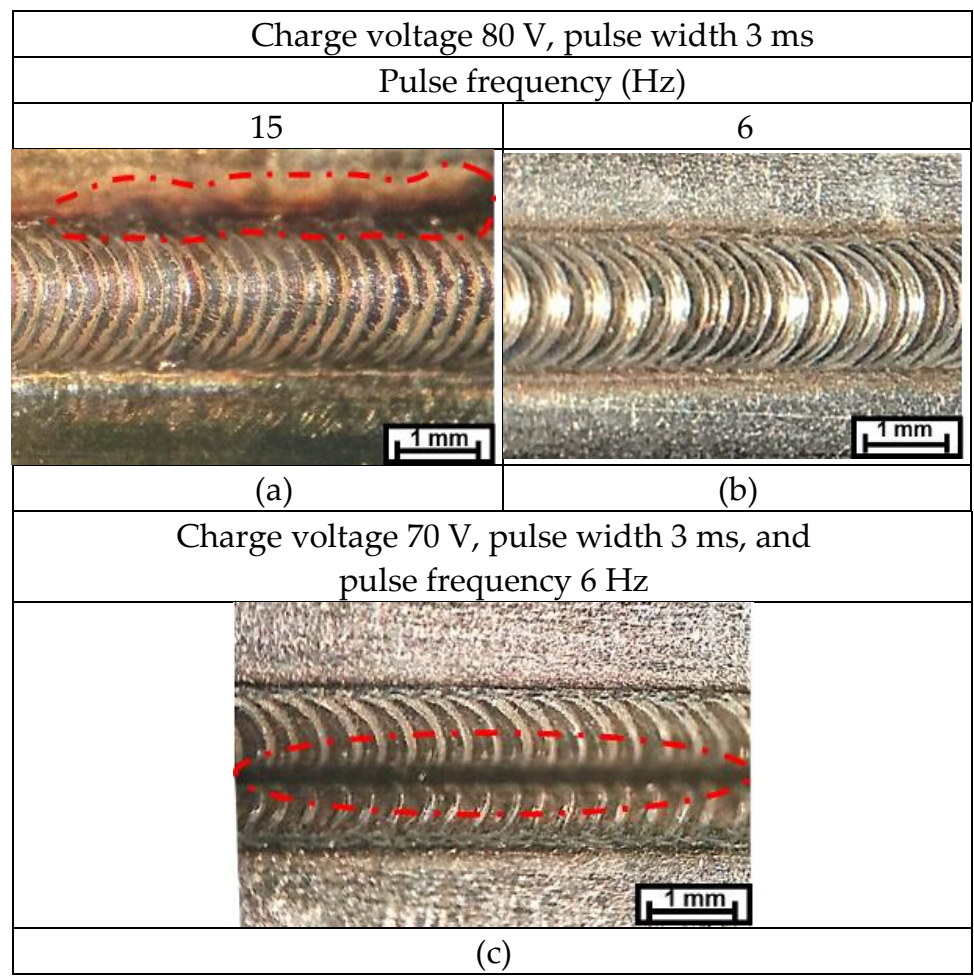

Figure 8. Weld appearance (a) Oxidation, (b) Good appearance with nice ripples, and (c) Lack of fusion.

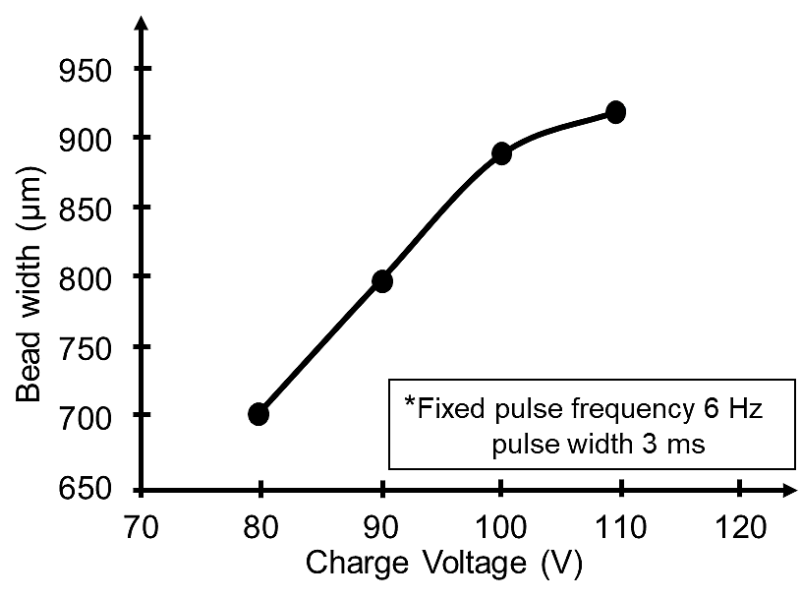

Figure 9. Effect of charge voltage on weld bead width.

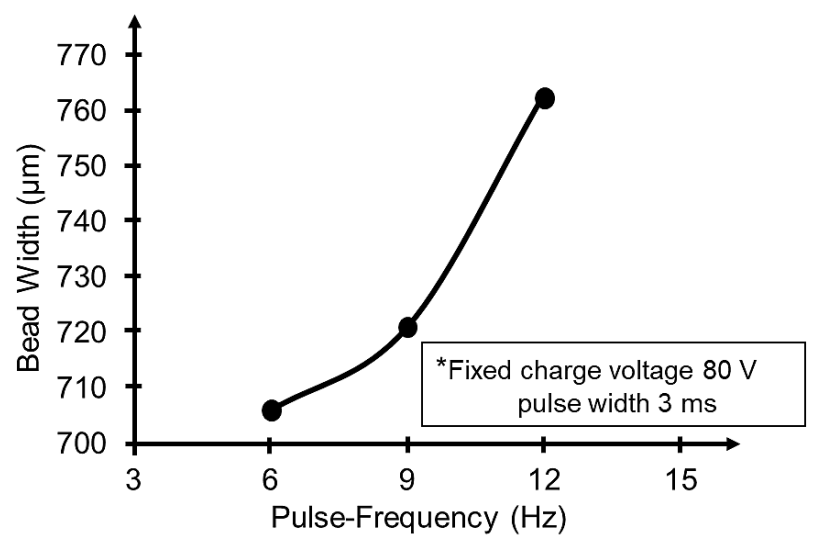

Figure 10. Effect of pulse frequency on weld bead width. 


\subsection{Effect of Laser Parameters on Area of Fusion, and Throat Size}

Figure 11 shows the example of a cross-sectional macro structure. The weld profiles could be analyzed in details on the cross-sectional area of the metallographic specimens. The specimens were prepared using a standard metallographic process including fine polishing and electrolytic etching with oxalic acid for revealing the fusion area. In the experiment, the charge voltage was set at $80 \mathrm{~V}$ and $90 \mathrm{~V}$, the pulse frequency was $6 \mathrm{~Hz}, 9 \mathrm{~Hz}$, and12 Hz, respectively, while the pulse width was set at constant of $3 \mathrm{~ms}$. The charge voltage and pulse frequency were adjusted in the experiments. Meanwhile, the macro structures were used to measure and analyze the area of fusion and the throat size of the influence when the heat was melting the stainless steel wire 316L.

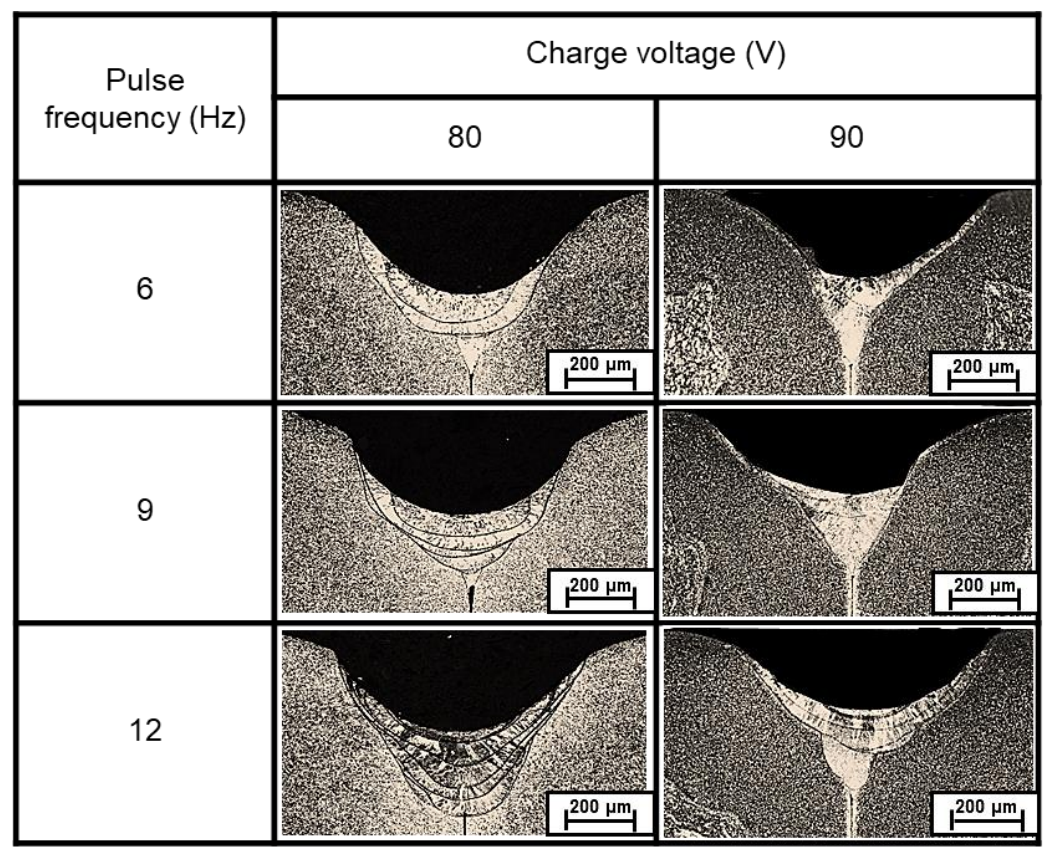

Figure 11. Cross-sectional macro structure.

Figures 12 and 13 show the results of macro analysis. The experimental results indicated that the increments of charge voltage and pulse frequency result in the increment of the fusion area and throat size. In particular, the increment of charge voltage will result in the increment of fusion area drastically. At the charge voltage of $110 \mathrm{~V}$ and the pulse frequency of $12 \mathrm{~Hz}$, the area of fusion and the throat size reach their maximum values. The tendency of the maximum tensile strength can be expected at this charge voltage and pulse frequency, because the increment of fusion area and throat size will lead to increment of joint strength as well. 


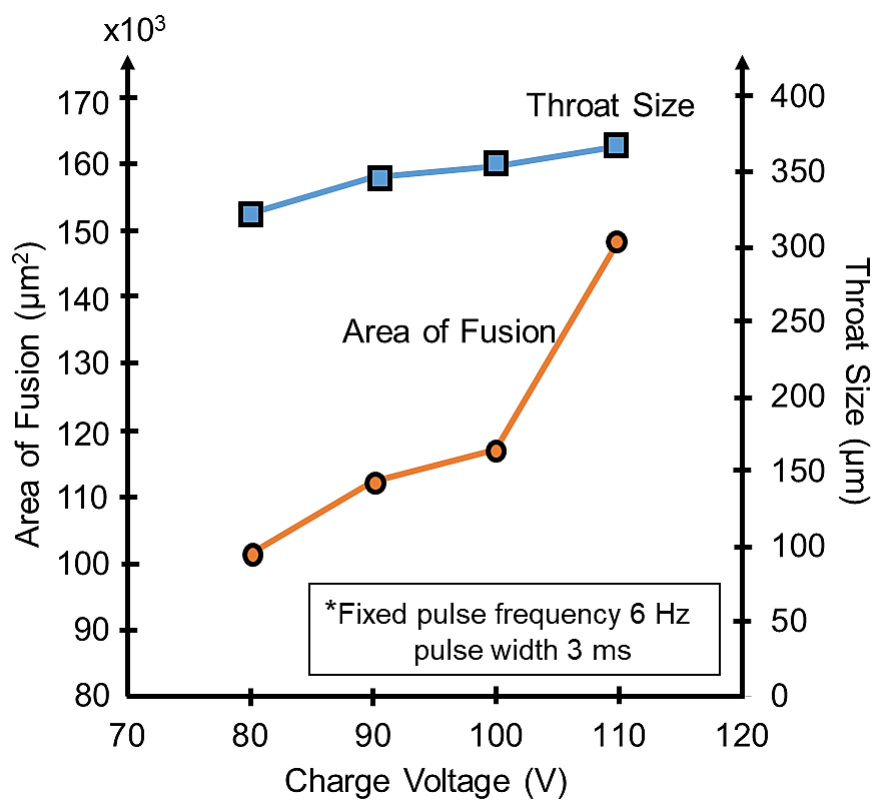

Figure 12. Effect of charge voltage on area of fusion and throat size.

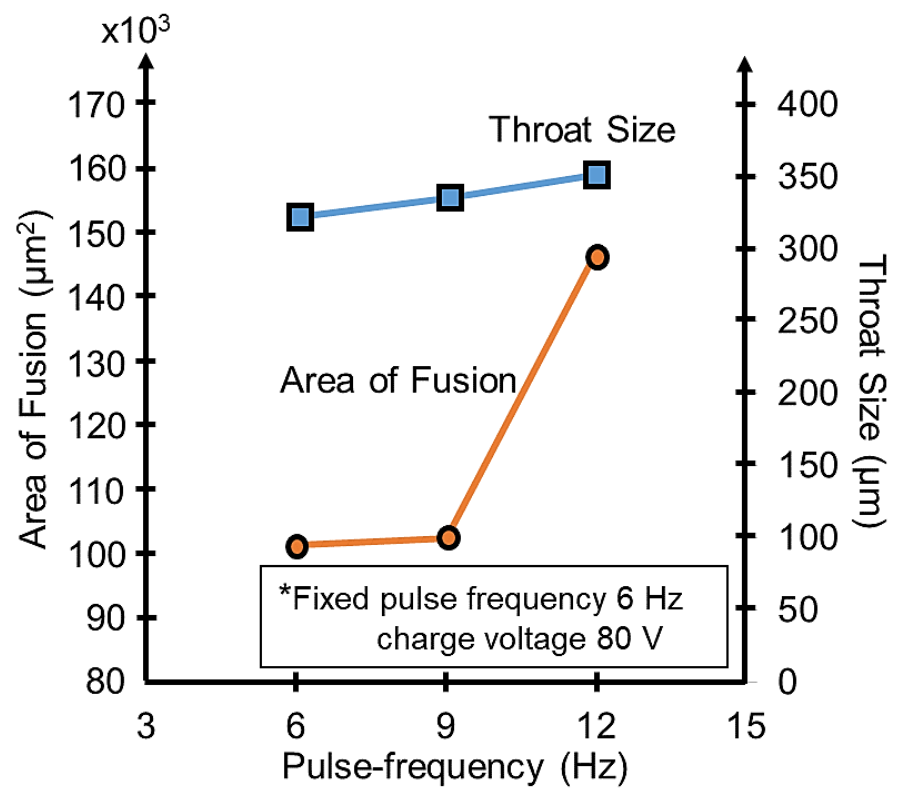

Figure 13. Effect of pulse frequency on area of fusion and throat size.

\subsection{Effects of Laser Parameters and Length of Welding Based on Mechanical Testing}

Regarding the $5 \mathrm{~mm}$ welding length, the mechanical testing results of the ultimate load at failure on weld joint are shown in Figure 14 for different pulse frequency at $6 \mathrm{~Hz}, 9 \mathrm{~Hz}$, and $12 \mathrm{~Hz}$. The charge voltage was adjusted stepwise at $80,90,100$, and $110 \mathrm{~V}$ while the pulse width was kept constant at $3 \mathrm{~ms}$. Figure 15 depicts the results of $10 \mathrm{~mm}$ welding length. Figures 14 and 15 show that the ultimate load at failure is affected by the increment of charge voltage and pulse frequency. Particularly, the increment of charge voltage results in the increment of sound bead as well as the joint strength. The experimental results of mechanical testing indicated that at the charge voltage of $110 \mathrm{~V}$, the highest ultimate load at failure could be obtained. Comparing to the case of charge voltage being at $80 \mathrm{~V}$, for the $5 \mathrm{~mm}$ welding length, the ultimate load at failure was increased from $800 \mathrm{~N}$ to $1200 \mathrm{~N}$ when the charge voltage was adjusted to $110 \mathrm{~V}$, as shown in Figure 14. For the $5 \mathrm{~mm}$ welding length, the ultimate load at failure was 
increased from $1400 \mathrm{~N}$ to $1700 \mathrm{~N}$ when the charge voltage was adjusted stepwise from $80 \mathrm{~V}$ to $110 \mathrm{~V}$, as shown in Figure 15.

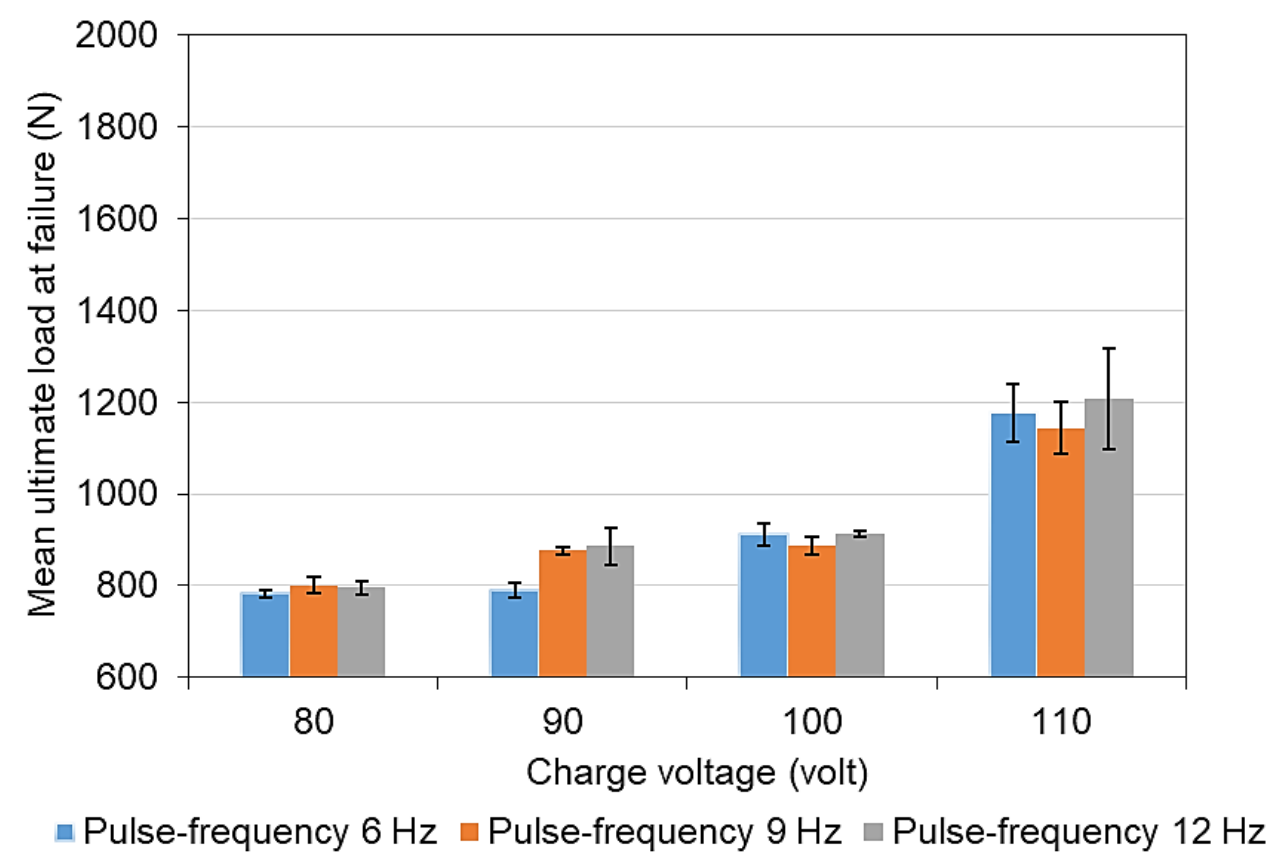

Figure 14. Effect of laser parameters on ultimate load at failure \pm standard deviation (SD) (length of welding $5 \mathrm{~mm}$ ).

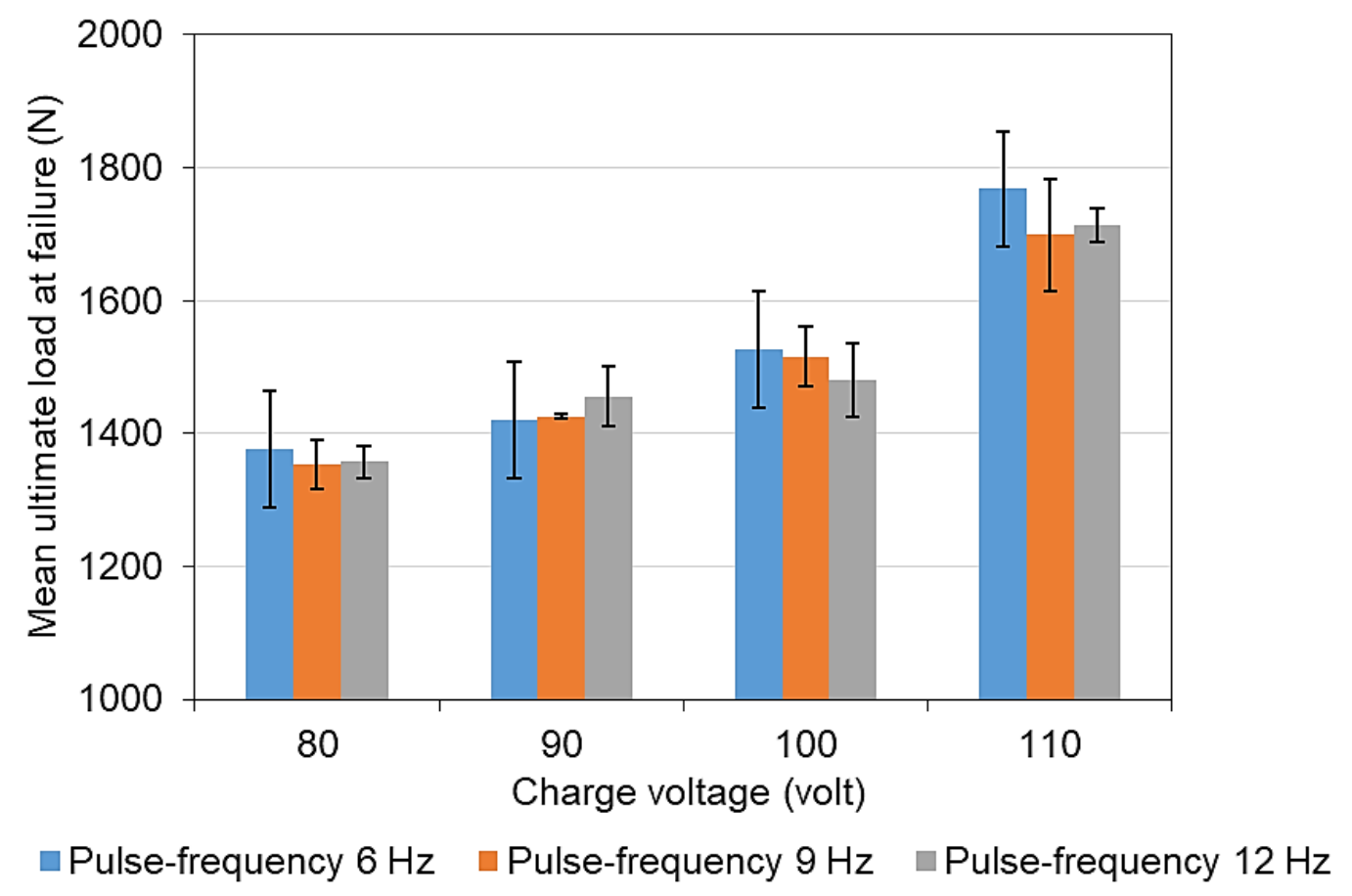

Figure 15. Effect of laser parameters on ultimate load at failure $\pm \mathrm{SD}$ (length of welding $10 \mathrm{~mm}$ ).

Regarding the $15 \mathrm{~mm}$ welding length, welding failure occurred at base metal. This phenomena indicated that the weld beads are stronger than the base metal. The experimental results of mechanical testing showed that the range of ultimate load at failure is approximately $1700-1800 \mathrm{~N}$ in the case of $15 \mathrm{~mm}$ welding length. Figure 16 indicated that an increase in charge voltage and pulse frequency did 
not affect the ultimate load at failure significantly in comparison to the situation where the length of welding is $15 \mathrm{~mm}$.

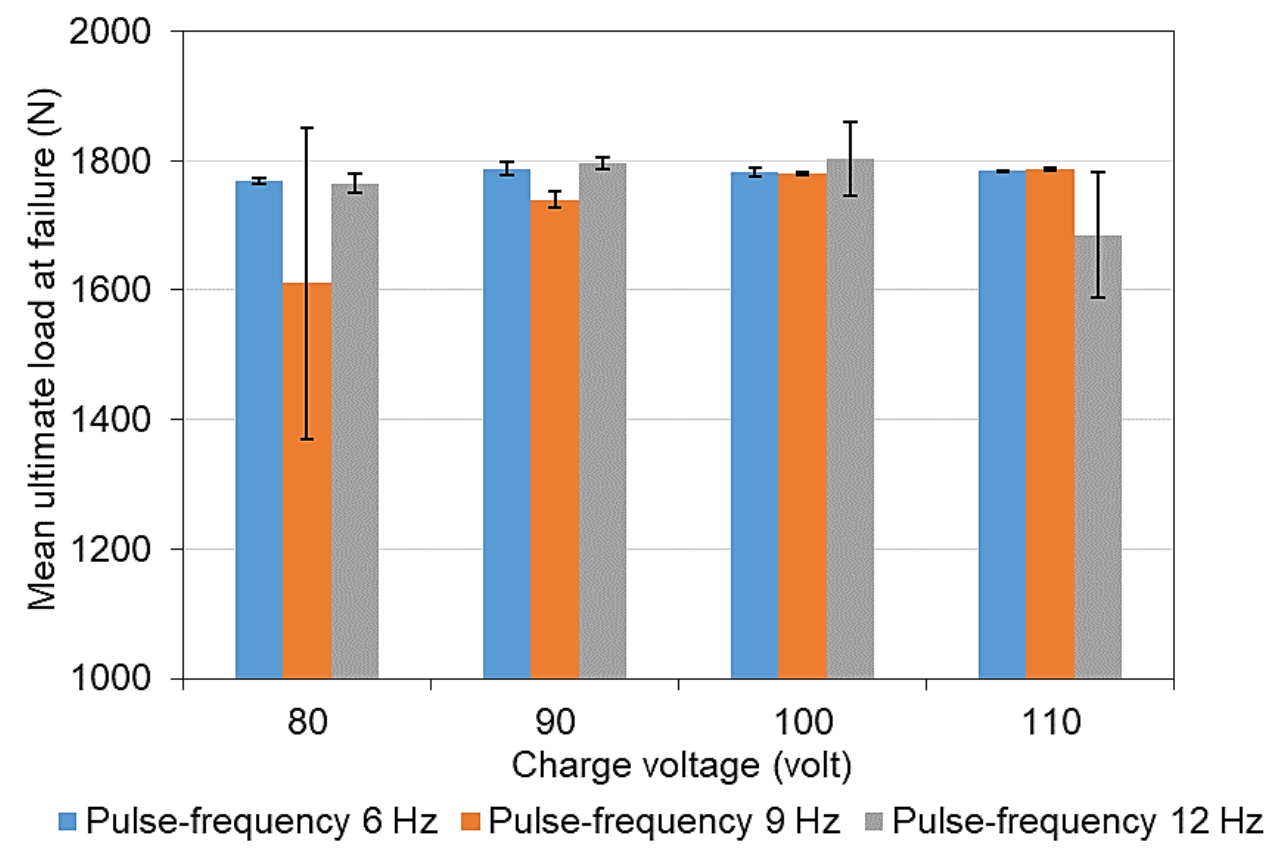

Figure 16. Effect of laser parameters on ultimate load at failure \pm SD (length of welding $15 \mathrm{~mm}$ ).

\subsection{Optimal Laser Parameters}

Adjusting the laser parameters and the welding length, the experimental results, considering the weld appearance and ultimate load at failure, can be analyzed to find the optimal laser parameters for welding on stainless steel 316L. In this study, the criteria for selecting the optimal laser parameters was designed to give a better ultimate load at failure or acceptable ultimate load at failure. The results are shown in Figure 17. The heat input was set at the lowest possible degree in the criteria. Figure 17 shows the laser parameters' process-window which indicates an adequate area of laser parameters.

In the experimental work, the example of weld appearance from the adequate area have a good weld appearance or nice ripples, free oxidation, and good joint strength. The increment of charge voltage and pulse frequency results in a higher heat input and ultimate load at failure. Furthermore, the increment of weld length brings about a higher ultimate load at failure as well. For example, the $5 \mathrm{~mm}$ welding length has the minimum ultimate load at failure but it is still within the acceptable range, as shown in Figure 14. At the welding length of 5, 10, and $15 \mathrm{~mm}$ in an adequate area of laser parameters, the experimental results show that all examples have ultimate load at failure and are within an acceptable range. In addition, all examples have the ultimate load at failure more than the traditional cerclage joint.

In summary, the adequate area of optimal laser parameters is chosen with the following conditions: The charge voltage should be at the range of $80-110 \mathrm{~V}$, the pulse frequency should be at the range of 6-9 Hz, while the pulse width was kept at constant of $3 \mathrm{~ms}$. In this area, the heat input is low and it is free of oxidation. 


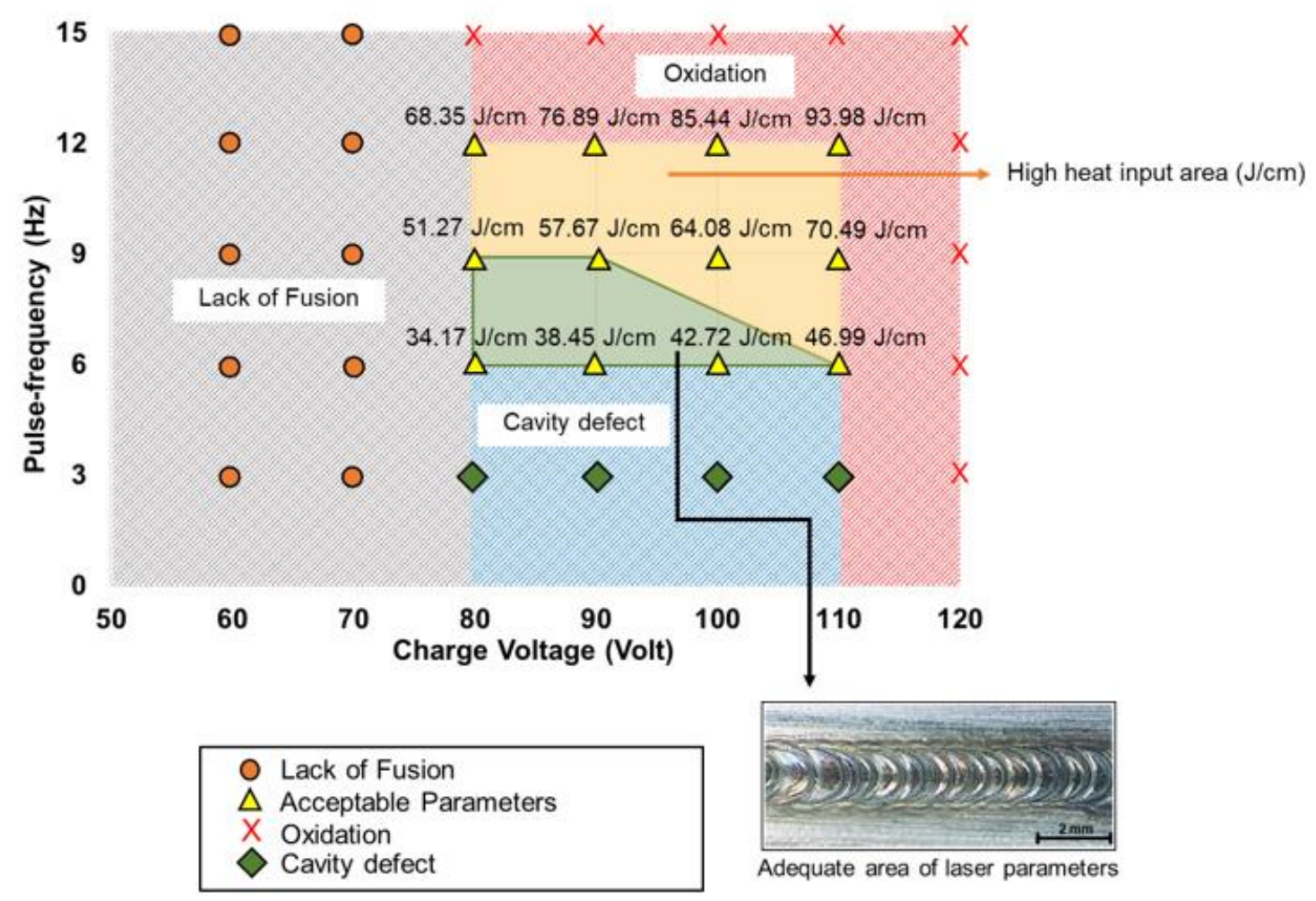

Figure 17. Adequate laser parameters.

\section{Discussion}

In this study, the cerclage wires with laser welded joints are proposed to replace the traditional cerclage wire. The objective is to resolve the untwisting problem of traditional cerclage wire as well as to increase the strength of wire joints. Laser welding technology was chosen and applied to the stainless steel wire joints because it is suitable for small pieces of specimen that require high precision.

The experiments of flare weld condition were carried out in the study to determine the range of adequate parameters during laser welding. The experimental results show that laser welding technology can be applied to weld on stainless steel wire 316L. With adequate laser parameters, the weld appearance has a nice ripple and free oxidation. The adequate area of the laser parameters obtained from the experiments includes the charge voltage range of $80-110 \mathrm{~V}$ and multiple frequency ranges of $6-9 \mathrm{~Hz}$ while the pulse width was kept at $3 \mathrm{~ms}$. The welded lengths of 5, 10, and $15 \mathrm{~mm}$ were also tested on the mechanical test to validate the joint strength. The results also show that the welded cerclage wire joints have the potential of larger joint strength and less loosening failure than that of traditional joint devices. Meanwhile, the ultimate load at failure is within acceptable range and higher than that of previous study [25].

\section{Conclusions}

This research examines the feasibility of laser welding and the effect of using laser weld on stainless steel wire 316L in a flare weld condition. It could be concluded that the stainless wire joints with fiber-laser weld are a promising alternative to traditional cerclage joint devices for modern femur surgery. However, one should be aware of safety procedures during the welding process to prevent any injuries to the patients in actual treatment. Several conclusions can be drawn as in the following:

- The area of the adequate laser parameters is the charge voltage range of 80-110 V and the pulse frequency of $6-9 \mathrm{~Hz}$ with the pulse width kept at $3 \mathrm{~ms}$. Experiments using the adequate laser parameters will result in a good weld appearance, low heat input, free oxidation, and ultimate load at failure in all of the weld lengths. 
- The increments of charge voltage and pulse frequency lead to an increase in the bead width, the area of fusion, and the throat size. The experimental results also show that the charge voltage has the main impact on the weld size and the weld shape.

- The increments of laser charge voltage and the increment of welding length will increase the ultimate load at failure. It was also reported that the increment of welding length has a greater influence on the ultimate load at failure than adjusting the laser parameters.

- The charge voltage is the significant parameter on the ultimate load at failure. The experimental result shows that the charge voltage of $110 \mathrm{~V}$ resulted in the highest ultimate load at failure.

- The experimental result shows that length of welding 5 and $10 \mathrm{~mm}$ failed at weld beads, but $15 \mathrm{~mm}$ failed at base metal because the weld bead is stronger than base metal. Moreover, it shows that the length of welding affects ultimate load at failure more than the adjustment of laser parameters.

In future works, the adequate laser parameters obtained from this study can be used to apply with laser welding to cerclage wire of an artificial bone. In addition, the heating simulation and actual system testing can be explored to investigate the thermal behavior of laser welding on cerclage wire in the conditions of temperature being within the acceptable range.

Author Contributions: Conceptualization, E.W. and Y.-T.W.; methodology, E.W.; software, N.T.; validation, N.T. and E.W.; formal analysis, N.T.; investigation, Y.-T.W.; resources, E.W.; data curation, N.T.; writing-original draft preparation, N.T.; writing-review and editing, Y.-T.W.; visualization, N.T. and Y.-T.W.; supervision, E.W.; project administration, E.W.; funding acquisition, Y.-T.W. All authors have read and agreed to the published version of the manuscript.

Funding: This research was partially funded by The Government Budget Grant of Thailand, grant number 9367 of Fiscal Year 2019 under E.W. The APC was funded by Ministry of Science and Technology, Taiwan, grant number MOST107-2221-E-032-044-MY2 under Y.-T.W.

Acknowledgments: The authors would like to thank the reviewers' efforts in reading the manuscript. Y.-T.W. would like to take this opportunity to thank Shieh Yih Machinery Industry Co., Ltd. for its continued support.

Conflicts of Interest: The authors declare no conflict of interest.

\section{References}

1. Stevens, S.S.; Irish, A.J.; Vachtsevanos, J.G.; Csongradi, J.; Beaupré, G.S. A biomechanical study of three wiring techniques for cerclage-plating. J. Orthop. Trauma 1995, 9, 381-387. [CrossRef] [PubMed]

2. Agarwala, S.; Menon, A.; Chaudhari, S. Cerclage wiring as an adjunct for the treatment of femur fractures: Series of 11 cases. J. Orthop. Case Rep. 2017, 7, 39. [PubMed]

3. Gordon, K.; Winkler, M.; Hofstädter, T.; Dorn, U.; Augat, P. Managing Vancouver B1 fractures by cerclage system compared to locking plate fixation-A biomechanical study. Injury 2016, 47, S51-S57. [CrossRef]

4. Ebraheim, N.A.; Sochacki, K.R.; Liu, X.; Hirschfeld, A.G.; Liu, J. Locking plate fixation of periprosthetic femur fractures with and without cerclage wires. Orthop. Surg. 2013, 5, 183-187. [CrossRef] [PubMed]

5. Angelini, A.; Battiato, C. Combination of low-contact cerclage wiring and osteosynthesis in the treatment of femoral fractures. Eur. J. Orthop. Surg. Traumatol. 2016, 26, 397-406. [CrossRef]

6. Angelini, A.; Battiato, C. Past and present of the use of cerclage wires in orthopedics. Eur. J. Orthop. Surg. Traumatol. 2015, 25, 623-635. [CrossRef]

7. Appleton, A.T.; Mantz, G.A.; Golden-Appleton, A.; Debenham, C.T.; Sandoval, T.N.; Wang, Q.; Hernandez, C.J. Manual of wiring techniques for orthopedic surgery. Tech. Orthop. 2019. [CrossRef]

8. Wähnert, D.; Lenz, M.; Schlegel, U.; Perren, S.; Windolf, M. Cerclage handling for improved fracture treatment. A biomechanical study on the twisting procedure. Acta Chir. Orthop. Traumatol. Cech. 2011, 78, 208-214.

9. Schultz, R.; Boger, J.; Dunn, H. Strength of stainless steel surgical wire in various fixation modes. Clin. Orthop. Relat. Res. 1985, 198, 304-307. [CrossRef]

10. Meyer, D.C.; Ramseier, L.E.; Lajtai, G.; Nötzli, H. A new method for cerclage wire fixation to maximal pre-tension with minimal elongation to failure. Clin. Biomech. 2003, 18, 975-980. [CrossRef]

11. Lenz, M.; Perren, S.M.; Richards, R.G.; Mückley, T.; Hofmann, G.O.; Gueorguiev, B.; Windolf, M. Biomechanical performance of different cable and wire cerclage configurations. Int. Orthop. 2013, 37, 125-130. [CrossRef] [PubMed] 
12. Ménard, J., Jr.; Émard, M.; Canet, F.; Brailovski, V.; Petit, Y.; Laflamme, G.Y. Initial tension loss in cerclage cables. J. Arthroplast. 2013, 28, 1509-1512. [CrossRef] [PubMed]

13. Zhou, Y.; Breyen, M.D. Joining and Assembly of Medical Materials and Devices; Elsevier: Amsterdam, The Netherlands, 2013.

14. Vannod, J.; Bornert, M.; Bidaux, J.-E.; Bataillard, L.; Karimi, A.; Drezet, J.-M.; Rappaz, M.; Hessler-Wyser, A. Mechanical and microstructural integrity of nickel-Titanium and stainless steel laser joined wires. Acta Mater. 2011, 59, 6538-6546. [CrossRef]

15. Wang, P.; Chen, X.; Pan, Q.; Madigan, B.; Long, J. Laser welding dissimilar materials of aluminum to steel: An overview. Int. J. Adv. Manuf. Technol. 2016, 87, 3081-3090. [CrossRef]

16. Örtorp, A.; Jemt, T. Clinical experiences with laser-welded titanium frameworks supported by implants in the edentulous mandible: A 10-year follow-up study. Clin. Implant. Dent. Relat. Res. 2006, 8, 198-209. [CrossRef]

17. Fornaini, C.; Merigo, E.; Vescovi, P.; Meleti, M.; Nammour, S. Laser welding and syncristallization techniques comparison: In Vitro study. Int. J. Dent. 2012, 2012, 720538. [CrossRef]

18. Fornaini, C.; Meleti, M.; Vescovi, P.; Merigo, E.; Rocca, J.-P. Laser welding and syncristallization techniques comparison: “Ex Vivo" study. Laser Ther. 2013, 22, 275-281. [CrossRef]

19. Fornaini, C.; Meleti, M.; Bonanini, M.; Lagori, G.; Vescovi, P.; Merigo, E.; Nammour, S. Laser welded versus resistance spot welded bone implants: Analysis of the thermal increase and strength. Sci. World J. 2014, 2014, 357074. [CrossRef]

20. Alves, P.; Lima, M.; Raabe, D.; Sandim, H.R.Z. Laser beam welding of dual-phase DP1000 steel. J. Mater. Process. Technol. 2018, 252, 498-510. [CrossRef]

21. Auwal, S.; Ramesh, S.; Yusof, F.; Manladan, S.M. A review on laser beam welding of titanium alloys. Int. J. Adv. Manuf. Technol. 2018, 97, 1071-1098. [CrossRef]

22. Wei, G.; Li, S.; Guo, Y.; Dang, Z. Fiber bragg gratings based cyclic strain measuring of weld toes of cruciform joints. Appl. Sci. 2019, 9, 2939. [CrossRef]

23. Akbari, M.; Kovacevic, R. Joining of elements fabricated by a robotized laser/wire directed energy deposition process by using an autogenous laser welding. Int. J. Adv. Manuf. Technol. 2019, 100, 2971-2980. [CrossRef]

24. Landowski, M. Influence of parameters of laser beam welding on structure of 2205 duplex stainless steel. Adv. Mater. Sci. 2019, 19, 21-31. [CrossRef]

25. Bostrom, M.; Asnis, S.E.; Ernberg, J.J.; Wright, T.M.; Giddings, V.L.; Berberian, W.S.; Missri, A. Fatigue testing of cerclage stainless steel wire fixation. J. Orthop. Trauma 1994, 8, 422-428. [CrossRef] [PubMed] 